American Journal of Agricultural and Biological Sciences 5 (1): 1-6, 2010

ISSN 1557-4989

(C) 2010 Science Publications

\title{
Effects of Novel Disk-type Furrow Opener Used in No-Tillage System on Micro Environment of Seed
}

\author{
${ }^{1}$ E. Seidi, ${ }^{1}$ S.H. Abdollahpour, ${ }^{2}$ A. Javadi and ${ }^{3}$ M. Moghaddam \\ ${ }^{1}$ Department of Agricultural Machinery Engineering, University of Tabriz, Tabriz, Iran \\ ${ }^{2}$ Department of Agricultural Machinery, Agricultural Engineering Research Institute, Karaj, Iran \\ ${ }^{3}$ Department of Agronomy, University of Tabriz, Tabriz, Iran
}

\begin{abstract}
Problem statement: Offset Double-Disk Opener (DDO) is a popular furrow opener in conservation tillage. It has some limitations such as negative suction to penetrate in the soil, hair pinning and mixing seed and fertilizer in the slot. Because of importance of separation of seed and fertilizer in the slot, by adding two horizontal mini disks to DDO a modified opener was made (MDO) which placed the fertilizer between and under two rows of seed. Approach: To consider performance of novel opener an indoor comparison test between DDO and MDO was performed at soil bin. The experiment was conducted with three working speeds $\left(3,6\right.$ and $\left.8 \mathrm{~km} \mathrm{~h}^{-1}\right)$, two bulk densities of soil (1.1 and $1.4 \mathrm{Mg} \mathrm{m}^{-3}$ ) and two levels of residues $\left(1\right.$ and 2 ton $\left.\mathrm{ha}^{-1}\right)$. The experimental design consisted in a $(3 \times 2 \times 2)$ complete randomized factorial with three replicates for each test. Moisture of seed furrow, separation of seed and fertilizer, hair pinning and resultant forces acting on the openers were used as assessing indexes. Results: There was no significant difference between soil moisture content in slots created by DDO and MDO at 0-4 cm depth, but at 4-8 $\mathrm{cm}$ the in the slot created by MDO moisture content was higher about $9 \%$. Horizontal force for both openers increased with increasing speed and soil bulk density. Vertical force for DDO was negative so it needed additional weight for penetrating in the soil, but vertical force for MDO was positive and, which can solve the challenge of penetration in the soil in DDO. In soft soil with heavy residues some trash was pushed by DDO into seed furrow (hair pinning) but at MDO seed were placed at clean groove. Lateral and vertical separation of seed and fertilizer was performed effectively by MDO ( 4.5 and $5 \mathrm{~cm}$, respectively) while DDO put seed and fertilizer close to each other. Conclusion: Overall, the Modified Offset Double-disks (MDO) had better performance. So by adapting this opener with no-tillage drillers it would possible to have higher yield in conservation tillage where the most appropriate opener is disk type.
\end{abstract}

Key words: Disk opener, force, seed and fertilizer, seedbed, moisture

\section{INTRODUCTION}

During the last decade conservation tillage has become more popular in many areas of the world. Because of its benefits in some countries such as Brazil, the rate of using this method among the farmers was so high that was named "explosion of no-tillage". The economic and environmental implications of conventional tillage and planting methods, such as soil erosion, soil compaction, high fuel consumption and inverting soil layers, will limit their use in the future. The main reason that such methods have been used for long time was preparation of fine seedbed before planting operation. Seedbed properties like penetration resistance, humidity concentration, porosity, particle dimensions and temperature, affect water absorption, seed germination, root growth and early plant establishment. In no-tillage farming nearly all of the soil manipulating operations, planting and application of fertilizers and pesticides are performed simultaneously by the seeder. Therefore, its structure and performance will strongly affect the crop yield. The performance of no-tillage seeders depends on several factors related to field conditions including type and amount of residues at soil surface, opener design (Karayel and Özmerzi, 2007), soil conditions and manner of using tool. In no-tillage practices, the characteristics of the seed-furrow play an important role in germination (Vamerali et al., 2006). It has been reported that the most important factors regulating germination, such as soil matric potential, temperature and sowing depth are affected by the soil/opener

Corresponding Author: $\quad$ E. Seidi, Department of Agricultural Machinery Engineering, University of Tabriz, Tabriz, Iran Tel: (+98) 41154329 20/(+98) 9188325484 Fax: (+98) 4115419744 
interaction (Tessier et al., 1991). A furrow opener is an important component of a seed drill or a planter. In general, a furrow opener cuts a furrow and allows the seeds or seedlings to be deposited before being partially covered by soil. The types of furrow openers used vary with soil and operating conditions. The common furrow openers used for conventional tillage are different from those used for no-tillage. Common types of furrow openers used for minimum and no-tillage systems are hoe, chisel, winged chisel, inverted $\mathrm{T}$ and disk furrow openers (Chaudhuri, 2001). There is comprehensive literature about the evaluation of commercially used openers at different situations, but as has been mentioned in reference number (Chaudhuri, 2001), most of the current works on the design performance of furrow openers has been devoted to study the horizontal and vertical forces acting upon them as a function of rake angle, forward speed, depth and width of the coulter.

Soil forces acting on soil working implements can simply be divided into two components:

i. Horizontal or draught force: The amount of force required to pull or push the implement through the soil

ii. Vertical force: The implement force assisting or preventing penetration into the soil

Ideally (i) must be as small as possible and (ii) must be directed downwards to assist penetration for major soil loosening operations, albeit implements with rake angles greater than approximately $70^{\circ}$ (such as disk openers) will produce upward vertical forces. These should be counterbalanced by implement weight or weight transfer from the tractor (Godwin, 2007). Generally, a furrow opener for a combined seed and fertilizer drill should fulfill the following objectives:

- The seed should be placed at the desired depth below the seedbed surface

- The seed should be covered with loose moist soil of sufficient thickness to protect it from direct radiation and from maintaining a high potential captivity for water vapor within the groove microenvironment (Choudhary et al., 1985)

- A desired vertical and lateral separation should be maintained between the seed and fertilizer. For most cereal crops, placement of fertilizers about $30 \mathrm{~mm}$ to the side and $20 \mathrm{~mm}$ below the seed is recommended (Choudhary et al., 1985; Baker and Afzal, 1986)

- Lateral and vertical width of seed spread should be minimized.
- The 3rd objective is the most challenging because the no-tillage producers found that the disk openers mix the seed and fertilizer in the seed slot. On the contrary the shank type openers which make good separation, causes too much soil disturbance which is against the purpose of no-tillage where lower soil disturbance is required. The high soil disturbance of furrow openers has become the major obstacle preventing producers from banding the fertilizer beside and under the seed in no-tillage system. Therefore, the future of this system relies on low-disturbance fertilizer banding openers, such as disk-type openers. This type has some advantages and disadvantages. In similar conditions, the disk opener may cause more progressive water loss in the soil layer above the seeds than the tine opener (Tessier et al., 1991). Furthermore, great drawbacks are also observed in wet clay soils where a permanent unclosed furrow is commonly created (Vamerali et al., 2006)

It is widely recognized that management of crop residues (trashes of previous crop) is one of the most important constraints for adopting no-tillage (Carter, 1994). Tine openers shift organic debris in the soil surface from the crop row sideways, with possible plugging of the seeder in the case of heavy residues, where as disk openers may lead to "hair pinning", with a consequent bad soil/seed contact and possible toxic effect on seedlings, although the rolling motion of a disk helps to cut through the soil surface residue (Rahman and Chen, 2001). Also, in crust forming soils better results are generally obtained by doubledisk opener (Hemmat and Khashoei, 2003). But the most effective planter with disk type opener developed in relation to banding fertilizer is "John Deer 1895 Separate Fertilizer Placement Air Drill" which uses separate units for laying fertilizer between each pair of seed rows. This planter has some problems such as high cost and excessive soil disturbance. In this project a unique regular disk drilling unit improved and used to drill both seed and fertilizer in the appropriate position. The aim of this research was to assess performance of a new opener. However, information about the performance of different furrow opener designs is rather limited in terms of soil type and soil conditions. There is still a lack of knowledge on the effect of furrow opener shape, structure, rake angle and width on soil reaction forces and furrow characteristics in different soil textures under variable soil conditions comprising different water contents and levels of compaction. The 
objective of the present study was to assess the effects of adding two inclined mini disks to common doubledisk opener on the characteristics of seedbed furrow and banding fertilizer.

\section{MATERIALS AND METHODS}

Experimental equipments: In this study a commercially used no-tillage Double-Disk Opener (DDO) was compared with a novel opener named as modified DDO (MDO). Double-disk opener consisted of two flat disks with a diameter of $390 \mathrm{~mm}$. One disk set $32 \mathrm{~mm}$ prior to work as a coulter and was aligned parallel to the traveling path vertically. Another disk was assembled with the angle of about $10^{\circ}$ as the distance of them at back was 60 $\mathrm{mm}$ (Fig. 1a.). This structure (offset double-disks) was also used in the modified opener, but two mini disks with diameters of $100 \mathrm{~mm}$ were mounted in the back (Fig 1b). The purpose of using this prototype was to lay fertilizer in the slot created by offset double-disks while mini disks create two horizontal grooves a little higher at both sides of the fertilizer slot. Such outline can ensure efficient vertical and horizontal separation between seed and fertilizer. Mini disks were assembled with the rake angle of $25^{\circ}$ in order to eliminate negative suction of disk implement for penetrating into the soil, because researchers found (Damora and Pandey, 1995) the furrow openers have lower draft at smaller width and wedge and a rake angle of $40^{\circ}$ or less. Also it has been proved that tendency to penetrate into the soil would be maximize if the rake angle of tool be about 23 (Godwin, 2007). The mini disks were so installed that their central axis was in the space between of the double-disks at behind. This led to imbalance of forces acting on mini disk due to frictional resultant forces inserted on the area of the mini disk had contact with the soil, out of the trace made by double-disks. Such arrangement also let mini disks to support the seed tubes.

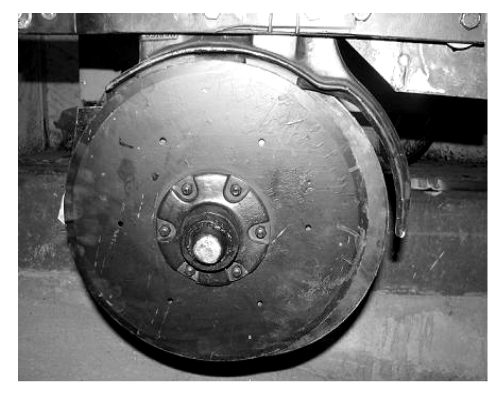

(a)

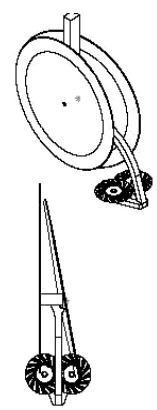

(b)
Fig. 1: Offset double-disks opener (a) and modified double-disks opener (b)
Testing facilities: The experiments were conducted at an indoor soil bin in Agricultural Engineering Research Institute (AERI) in Karaj, Iran. The soil bin is $1.8 \mathrm{~m}$ wide, $25 \mathrm{~m}$ long and $1 \mathrm{~m}$ deep and contains a loamy sand soil $\left(800 \mathrm{~g} \mathrm{~kg}^{-1}\right.$ sand and $100 \mathrm{~g} \mathrm{~kg}^{-1}$ clay by weight). A 399 Messy Ferguson tractor equipped with speed and slippage sensor was used as power source. A carriage for moving the implements was attached to the tractor via two load cells installed on the hydraulics arms of tractor. For detecting smaller variations an octagonal dynamometer located between carriage and the implements used. By using such dynamometer horizontal force (draft), vertical force and momentum were measured separately. To obtain a definite working depth and maintaining it a hydraulic cylinder installed on carriage was used. To maintain uniform soil conditions of soil moisture content and bulk density throughout the tests, an equal amount of water was sprayed over the soil and left to infiltrate. Then the soil was tilled by a spike type roller at a greater depth than the maximum experimental working depth designed. The last step for soil preparation was leveling and compact it with smooth roller was loaded by two hydraulic arms for making different pressures. The final soil moisture and dry bulk density was measured before each test runs.

Experimental design and measurements: A $(3 \times 2 \times 2)$ completely factorial experiment with three working speeds $\left(3,6\right.$ and $8 \mathrm{~km} \mathrm{~h}^{-1}$ ) and two soil bulk densities (1.1 and $1.4 \mathrm{Mg} \mathrm{m}^{-3}$ ) and two concentration of residue ( 1 and 2 ton $\mathrm{ha}^{-1}$ ) was conducted for each tool. The selected levels are the most common in no-tillage operation. Each treatment was replicated three times. The selected depth for planting seed was $6 \mathrm{~cm}$. Before test runs, three random soil cores $(80 \mathrm{~mm}$ diameter $)$ were taken for measuring initial soil moisture content and dry bulk density. The sample was dried at $105^{\circ}$ for $24 \mathrm{~h}$. Then, the tests were run and after $96 \mathrm{~h}$ soil moisture in two depths of $0-4$ and $4-8 \mathrm{~cm}$ in each seed slot were measured (Abbaspour-Gilandeh et al., 2009). The forces were measured online by octagonal dynamometer and the data were recorded by appropriate data acquisition instrument. After each test run, the soil surface disturbance profile and the crosssectional area disturbed by the tool were measured in three random locations. At such locations a profile was made and then two pictures of each furrow were taken with respect to original soil surface. In order to analyze the pictures in the computer program, a ruler was put in the furrow when a picture was taken. Then the pictures were split into square mesh in computer to consider amount of translocated soil. Effect of soil bulk density 
and traveling speeds on the soil reactions were assessed by least significant difference method $(\mathrm{p} \leq 0.001)$.

In order to study placement of fertilizer and seed some color balls were used. They were a little denser than real seeds to facilitate moving seeds at the horizontal end of seed tube, because conducting seeds into horizontal grooves without air drilling facility was difficult. The positions of seeds and fertilizer were measured with the accuracy of one $\mathrm{mm}$.

\section{RESULTS}

\section{Soil forces:}

Horizontal force (draft): The greater was the bulk density of the soil, the greater was the draft force measured in both openers. Also at each bulk density the rate of increase in draft force was larger at high speed (Fig. 2). Although, on the average DDO exhibited lower draft force, but it should be noted that the MDO works as two furrow openers and drills two rows of seeds and appropriate amount of fertilizer between them.

Vertical force: Generally, the tools with the rake angle greater than $70^{\circ}$, such as disk type tools, encountered with upward forces from soil. It means they do not have tendency to penetrate into soil and therefore, an additional force is needed (Godwin, 2007). In order to use the DDO at compacted soil with bulk density of $1.4 \mathrm{Mg} \mathrm{m}^{-1}$, about $200 \mathrm{~kg}$ weight was needed to ensure good penetration of the tool. Fig. 3 shows the vertical resultant forces acting on the both openers at different speeds. The positive values indicate downward forces acting on the tools and the negative values represent upwards forces which tend to push the tools out of the soil. By increasing the working speed, soil penetration of the tools improved. For DDO this effect was more pronounced at lower bulk density of soil.

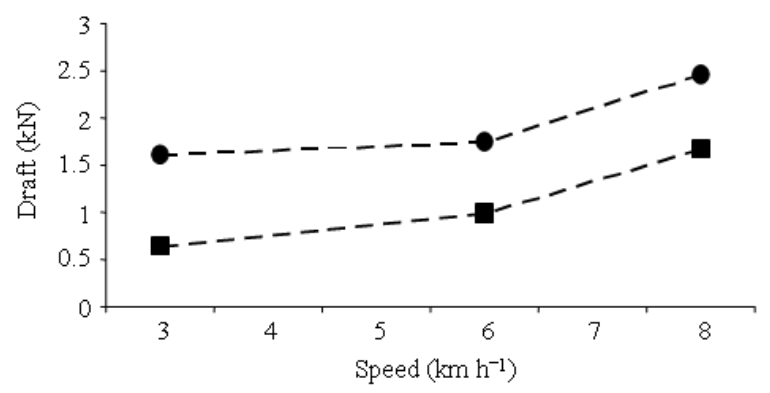

Fig. 2: Relationship between working speed and horizontal force (draft) in soil with $1.4 \mathrm{Mg} \mathrm{m}^{-3}$. $(\bullet) \mathrm{MDO},(\bullet) \mathrm{DDO}$
In contrary, increasing of speed in MDO was more effective in more compacted soil. At the same conditions of soil bulk density and speed, MDO had higher downward forces as it became nearly zero at the worst situation and had positive values at other conditions which can ensure more even planting depth.

Hair pinning: The basic rules for the conventional seeding of cereal and other crops could also be applied to the direct drilling of these crops into stubble. The seed is ideally placed in a moist soil on a firm seedbed, $25-60 \mathrm{~mm}$ from the soil surface, with the soil packed tightly above the seed for optimum moisture contact and minimum soil drying. In a heavy trash, seed placement of DDO was poor. In a heavy surface trash $\left(2\right.$ ton $\mathrm{ha}^{-1}$ ) failure of the opener to cut through the surface residue resulted in seed furrow and seedbed partially filled with residue. In lighter trash conditions $\left(1\right.$ ton $\mathrm{ha}^{-1}$ ) and in lower bulk density of soil, the trash was pushed to the bottom of the furrow without being cut (Fig. 4). In this case seed was placed on the trash and covered with a small amount of trash and soil.

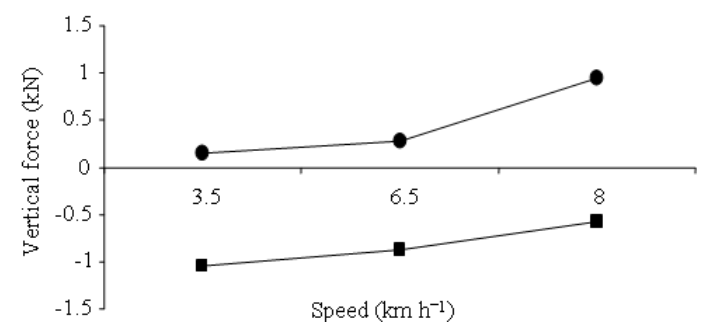

Fig. 3: Relationship between working speed and vertical force in soil with $1.4 \mathrm{Mg} \mathrm{m}^{-3}$. (•) MDO, (घ) DDO

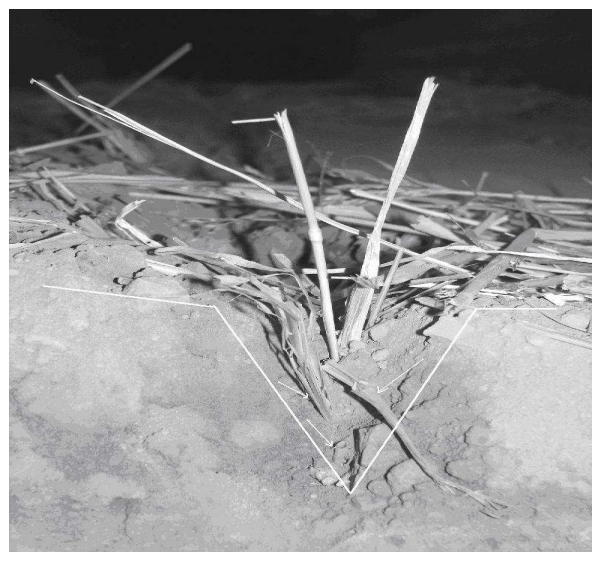

Fig. 4: Hair pinning in the slot crated by double-disks opener 
Am. J. Agri. \& Biol. Sci., 5 (1): 1-6, 2010

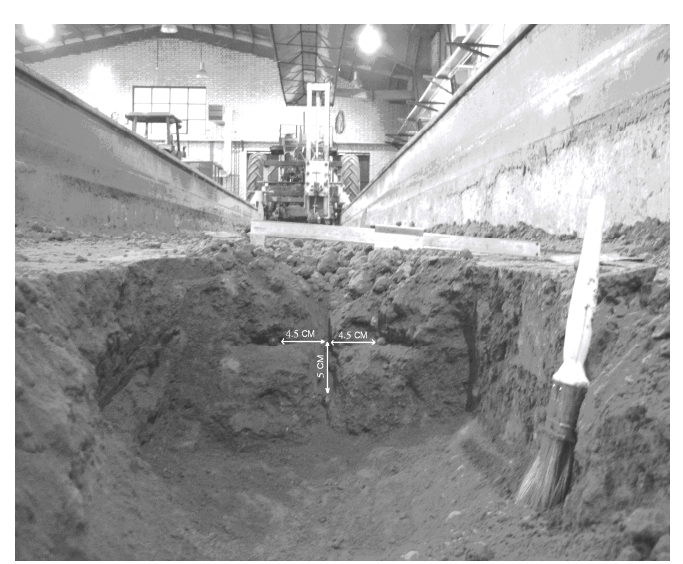

Fig. 5: Lateral and vertical separation of seed and fertilizer in the slot created by modified doubledisks opener

This reduces the contact between the seed and the soil which is necessary for good germination. But the seed furrow was better in the soil with high bulk density covered by light amount of trash. However, because of lack of direct relation between horizontal seed grooves in MDO and soil surface, no trash was observed in seed groove, whereas some straw was pushed in the main furrow created by double-offset disks. As the main furrow only contains the fertilizer, it would not affect seed-soil contact. Also in the horizontal seed grooves residue roots, were cut by mini disks efficiently.

Seed and fertilizer placement and separation: Considering lateral and vertical distances between seed and fertilizer, in DDO both seed and fertilizer tubes were next to each other between two disks and consequently, the seed and fertilizer delivered to soil very closely. At the best conditions (a low density soil without surface residue) after delivering the fertilizer at front, a thin layer of soil came back into furrow before seed fall on the soil. Although this layer can act as a buffer protecting seed from fertilizer toxicity before germination, but it is not appropriate position for fertilizer in the next stage of plant life (Baker and Afzal, 1986). In MDO, fertilizer was delivered to the bottom of main furrow created by offset double-disks. Because of deeper working depth the main furrow was bigger and therefore, higher amounts of fertilizer could be placed. Two horizontal mini disks created two horizontal grooves as seedbed at middle of main furrow. The depth of these furrows was $6 \mathrm{~cm}$. The seeds were placed in these furrows as their horizontal distance from each other was about $11 \mathrm{~cm}$. The fertilizer was banded between them and their horizontal separation was $4.5 \mathrm{~cm}$ on the average. Vertical distance between seeds and fertilizer was about $5 \mathrm{~cm}$ (Fig. 5).

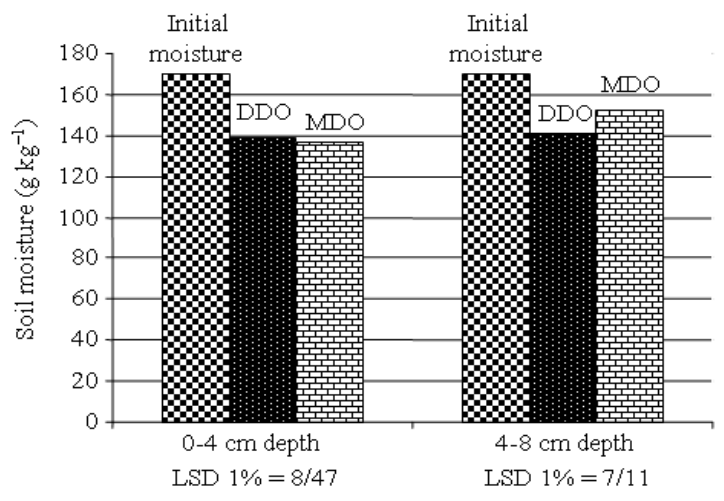

Fig. 6: Soil moisture content at seed furrows after $96 \mathrm{~h}$

Slot moisture: Because of different degree of soil disturbance between the openers, different amount of moisture loss in the slots can be expected. Soil moisture at $0-4$ and $4-8 \mathrm{~cm}$ were measured after $96 \mathrm{~h}$. Although at $0-4 \mathrm{~cm}$ depth the slot moisture was a little higher for DDO, but the difference was not significant. At the depth of $4-8 \mathrm{~cm}$ the moisture of seed slot was significantly higher for MDO (Fig. 6).

\section{DISCUSSION}

Higher draft force in MDO was predicted. In some literature, (Godwin, 2007; Rahman and Chen, 2001) relationship between draft force and cross section of disturbed soil proved. Actually, in the MDO opener the amount of soil disturbance increased due to higher rate of soil failure at wider cross section, this in turn increased the energy consumed for friction and acceleration of disturbed soil.

About vertical forces acting on the disk tools it has been found that at higher speed tendency to penetrate increase (Morrison, 2002). But in this research MDO had better penetration in each level of aped. This happened due to low rake angle of mini disks which generates a vertical force component from draft inducing vertical suction which suppresses vertical resultant force acting on offset disks. This helps to push the opener into soil surface. It means there is no need to use excessive weight in construction of opener and, of course, this would decrease fuel consumption.

In order to placement of seed and fertilizer, the best situation is to ensure both lateral and vertical separation 3 and $4 \mathrm{~cm}$, respectively (Afzal, 1986; Vamerali et al., 2006). This happened by using MDO, of course, the horizontal and vertical distances were a little bigger.

Soil moisture content in depth of $4-8 \mathrm{~cm}$ was lower for MDO. Probably this happened due to higher soil surface disturbance because of its wider working width. It proved that the higher soil disturbance, the higher water losing from furrow (Tessier et al., 1991). But 
higher moisture content at $4-8 \mathrm{~cm}$ in MDO could be due to the position of seed in the horizontal grooves which closed after opener passing, automatically under the weight of upper layers of soil or surcharge load impressed by optional furrow closing wheels. Consequently, the relationship between seed groove and atmosphere would be eliminated which helps to trap the humidity in slot. On the other hand, offset disks work deeper in MDO (about $11 \mathrm{~cm}$ ) and mix the wetter layers of deeper soil with the dryer soil of upper layers. Therefore, increasing the concentration of water vapor in fertilizer furrow can decrease the rate of water evaporation from seed slot to reach a balance with micro-environment of the furrow. But with regard to DDO, because of creating "V" shape furrow which is filled partially with loose soil, the rate of evaporation was higher and seed groove soil was dryer.

\section{CONCLUSION}

Offset double-disks opener is one of the most common furrow opener used in no-tillage driller, but it has some disadvantages such as hair pinning, negative suction and poor separation of seed and fertilizer. By adding two horizontal mini disks to the main structure of DDO some improvement were achieved. Negative suction of DDO to penetrate into soil became zero at the most difficult conditions (the highest soil bulk density and traveling speed) and positive at other conditions which helped to make it possible to fabricate lighter no-tillage driller and, of course, better using of disk type openers in firm soils. Seed can be placed in a clean slot by MDO without trashes which guarantee good contact between soil and seed for better moisture absorption. Also, horizontal seed grooves can be closed by closing wheels from soil surface because direction of loading is perpendicular to slot and consequently moisture content of slot would be conserved more efficiently. The most important achievement by MDO was good lateral and vertical separation of seed and fertilizer. MDO placed two rows of seeds and appropriate amount of fertilizer between them simultaneously as vertical distance between seed and fertilizer was $4.5 \mathrm{~cm}$ and horizontal distance was $5 \mathrm{~cm}$. Of course by increasing working speed the penetration tendency by both openers were improved.

\section{REFERENCES}

Abbaspour-Gilandeh, Y., V.R. Sharabiani and A. Khalilian, 2009. Effects of tillage methods on soil fragmentation in loamy-clay soils. Am. J. Agric. Biol. Sci., 4: 131-136. DOI: 10.3844/ajabssp.2009.131.136
Baker, C.J. and C.M. Afzal, 1986. Dry fertilizer placement in conservation tillage: Seed damage in direct drilling no tillage. Soil Till. Res., 7: 241-250. DOI: 10.1016/0167-1987(86)90467-8

Carter, M.R., 1994. A review of conservation tillage strategies for humid temperate regions. Soil Till. Res., 31: 289-301. DOI: 10.1016/01671987(94)90037-X

Chaudhuri, D., 2001. Performance evaluation of various types of furrow openers on seed drills-a review. J. Agric. Eng. Res., 79: 125-137. DOI: 10.1006/jaer.2000.0688

Choudhary, M.A., G.P. Yu and C.J. Baker, 1985. Seed placement effects on seedling establishment in direct drilled fields. Soil Till. Res., 6: 79-93. DOI: 10.1016/0167-1987(85)90008-X

Damora, D.P. and K.P. Pandey, 1995. Evaluation of performance of furrow openers of combined seed and fertilizer drills. Soil Till. Res., 34: 127-139. DOI: $10.1006 /$ jaer.2000.0688

Godwin, R.J., 2007. A review of the effect of implements geometry on soil failure and implement forces. Soil Till. Res., 97: 331-340. DOI: 10.1016/j.still.2006.06.010

Hemmat, A. and A.A. Khashoei, 2003. Emergence of irrigated cotton in flat land planting in relation to furrow opener type and crust-breaking treatments for cambisoils in central Iran. Soil Till. Res., 70: 153-162. DOI: 10.1016/S0167-1987(02)00157-5

Karayel, D. and A. Özmerzi, 2007. Comparison of vertical and lateral seed distribution of furrow openers using a new criterion. Soil Till. Res., 95: 69-75. DOI: 10.1016/j.still.2006.11.001

Rahman, S. and Y. Chen, 2001. Laboratory investigation of cutting forces and soil disturbance resulting from different manure incorporation tools in a loamy sand soil. Soil Till. Res., 58: 19-29. DOI: 10.1016/S0167-1987(00)00181-1

Tessier, S., G.M. Hyde, R.I. Papendick and K.E. Saxton, 1991. No-till seeders effects on seed zone properties and wheat emergence. Till. ASAE, 34: 733-739.

Tessier, S., K.E. Saxton, R.I. Papendick and G.M. Hyde, 1991. Zero-tillage furrow opener effects on seed environment and wheat emergence. Soil Till. Res., 21: 347-360. DOI: 10.1016/0167-1987(91)90030-2

Vamerali, T., M. Bertocco and L. Sartori, 2006. Effects of a new wide-sweep opener for no-till planter on seed zone properties and root establishment in maize Zea mays L.: A comparison with doubledisk opener. Soil Till. Res., 89: 196-209. DOI: 10.1016/j.still.2005.07.011 